\title{
EDITORIAL
}

\section{Bending the Trends}

\author{
Karen DeSalvo, MD, MPH, MSc ${ }^{1}$ \\ Andrea Harris, MSc ${ }^{2}$ \\ ${ }^{1}$ New Orleans, Lousiana \\ ${ }^{2}$ Washington, DC
}

Ann Fam Med 2017;15:304-306. https://doi.org/10.1370/afm.2101.

I $\mathrm{n}$ this issue of the Annals of Family Medicine, Dr Johansen adds to our understanding that despite efforts to control health care costs over the past 2 decades, we are quickly approaching a reality in which health care spending subsumes one-fifth of our economy, which is well above our international peers. ${ }^{1,2}$ As Dr Johansen notes, this rising spending is the result of continued utilization of higher cost services such as specialty and hospital care, as well as increased prices. Increases in health care spending are not associated with better outcomes or more equitable health. The health status of the people in the United States continues to be burdened with high rates of chronic disease and for the first time in generations, life expectancy is declining. ${ }^{3}$

The Triple Aim has been the national call to action that drives the goals of "improving the experience of care, improving the health of populations, and reducing per capita costs of health care." ${ }^{\prime \prime 4}$ To date, the strategy for achieving the Triple Aim has been predominately focused on improving the health care system through the adoption of value-based payment design in lieu of fee-for-service payment models, and on reducing variability in health service delivery. ${ }^{5}$ Early results indicate that cost growth is slowing and that innovative delivery models are improving quality and safety of care and decreasing unnecessary utilization such as avoidable hospital readmissions. ${ }^{6}$

\section{ADDRESSING THE SOCIAL NEEDS}

As delivery system reform has progressed, payers and health systems are assuming greater financial risk for

Conflicts of interest: authors report none.

\section{CORRESPONDING AUTHOR}

Karen DeSalvo, MD, MPH, MSc

232 Rio Vista Avenue

Jefferson, LA 70121

karen.desalvo@gmail.com health outcomes. Even the highest performing health systems are finding the medical model insufficient to adequately constrain costs and improve health outcomes due to the social needs of their patients. Failure to appropriately contextualize the health care plan can have significant consequences. ${ }^{7}$ Providing the best quality care for a patient with COPD in the clinical setting is an important goal. But if that patient cannot afford the medication or does not have access to transportation for their follow up care, their disease will quickly become uncontrolled, leading to worse health outcomes and higher utilization-related costs.

In response, public and private payers are piloting payment models that encourage the health care system to address social needs. For example, the Centers for Medicare and Medicaid Services recently announced the Accountable Health Communities demonstration model that encourages health care providers to build linkages with community organizations, such as Meals on Wheels, that can address their patients' social needs such as hunger or poor nutrition. ${ }^{8}$ Pay-for-success models, such as the South Carolina Nurse Family Partnership, are a version of social impact bonds that go a step further by encouraging community linkages and providing resources to support them. ${ }^{9}$

Community-oriented primary care providers are especially likely to welcome these types of payment models and the new technologies that support them because addressing the social factors of health is fundamental yet complex and rarely compensated. Encouragingly, evidence is building that addressing social factors improves health outcomes at a lower $\cos ^{\mathrm{t}^{10,11}}$; investing in coordinators who connect patients to social services can save between $\$ 15$ and $\$ 72$ billion annually. ${ }^{12}$

\section{ADDRESSING THE SOCIAL DETERMINANTS OF HEALTH}

Though integrating health care with social care is critical for improving health at a lower cost, reforming 
payment models alone is insufficient. ${ }^{13}$ Leaders must work to create healthy communities by addressing factors further upstream such as the environment, housing, transportation, and access to healthy food and safe spaces. By moving to a public health model, rather than a purely medical model, communities can create the conditions where everyone can be healthy and reverse health disparities. ${ }^{14-16}$

This undertaking requires collaboration and resources from many community sectors, and cannot be the sole responsibility of the health care system. The promising news is that communities across the country are pioneering a new approach to improving the health of their communities by addressing all the determinants of health. ${ }^{17,18}$ These "Public Health 3.0" communities are coming together to create new umbrella organizations to set a shared vision and shared goals about the health of their communities, to share data and funding, and to coordinate activities aimed at improving health. Their efforts are showing promise, including improvements in health outcomes and reductions in mortality. ${ }^{19,20}$ For patients with COPD, this would mean not only that their community's health care system can link them to support services for their social needs, but also that they can live in smoke-free housing.

\section{DISRUPTION NEEDED TO CREATE AFFORDABLE, EQUITABLE HEALTH FOR ALL}

These collaborations will only be successful if we address the social needs of our patients and make structural changes to funding and accountability for individual and community health. First, clinical teams should identify and support the social needs of our patients with the rigor they would apply to avoiding other medical errors. Second, health systems should show leadership by holding their executives accountable not only for outcomes for their patient population, but also for the health outcomes of their communities. Third, communities can only advance health if they have access to timely, specific data. Data availability will require continued focus on creating a culture of data sharing for public health advancement. Fourth, federal and state policy makers should work with states to maximize funding flexibility to accommodate local innovations aimed at investing in upstream social determinants of health. Fifth, education of the clinical and public health workforce should encourage an understanding of the social determinants of health and provide training in working across sectors. Sixth, it will require an increase in investment in the social determinants of health. Currently, US spending on social services is on par with other Organisation for Economic Co-operation and Development countries, but we spend a significantly greater proportion on health care. This spending pattern may need to change if we seek to improve health outcomes. ${ }^{21}$

\section{CONCLUSION}

The health system that Johansen describes is one that has been on a relentless path of increasing high-cost utilization without clear return on investment. While the health system is working to achieve the triple aim by improving the health care delivery system, it alone will not be sufficient to bend the cost curve and reverse declining life expectancy and increasing disparities. This will be true even if we build better delivery models that address the social needs of patients. To improve overall population health, we will need to embrace disruptive models of health that address health care needs as well as the social factors and enable leaders to build healthier communities that support affordable, equitable health for all.

To read or post commentaries in response to this article, see it online at http:I/www.AnnFamMed.org/content/15/4/304.

Key words: health care reform; health care costs; social determinants of health; health equity; public health; Public Health 3.0

Submitted March 22, 2017; accepted April 26, 2017.

\section{References}

1. Johansen ME. Comparing medical ecology, utilization, and expenditures between 1996-1997 and 2011-2012. Ann Fam Med. 2017;15(4):313-321.

2. National Health Expenditure Projections 2016-2025. Centers for Medicare \& Medicaid Services. https://www.cms.gov/ResearchStatistics-Data-and-Systems/Statistics-Trends-and-Reports/NationalHealthExpendData/Downloads/proj2016.pdf.

3. Xu J, Murphy SL, Kochanek KD, Arias E. Mortality in the United States, 2015. NCHS Data Brief No. 267; December 2016. https:// www.cdc.gov/nchs/data/databriefs/db267.pdf.

4. Berwick DM, Nolan TW, Whittington J. The triple aim: care, health, and cost. Health Aff (Millwood). 2008;27(3):759-769.

5. Burwell SM. Setting value-based payment goals-HHS efforts to improve U.S. health care. N Engl J Med. 2015;372(10):897-899.

6. Fryhofer SL, Seshmani M, DeSalvo KB, Conway PH. Progress and a path forward. N Engl J of Med Catalyst. 2017. http://catalyst.nejm. org/delivery-system-reform-progress-path. Published Feb 5, 2017. Accessed Mar 20, 2017.

7. Weiner SJ, Schwartz A. Contextual errors in medical decision making: Overlooked and understudied. Acad Med. 2016;91(5):657-662.

8. Alley DE, Asomugha CN, Conway PH, Sanghavi DM. Accountable health communities-addressing social needs through Medicare and Medicaid. N Engl J Med. 2016;374(1):8-11.

9. South Carolina Pay for Success Model for Nurse Family Partnership. https://www.scdhhs.gov/sites/default/files/2-16-16-SC-NFP-PFS-FactSheet_3.pdf.

10. Edwards PK, Levine M, Cullinan K, Newbern G, Barnes CL. Avoiding readmissions-support systems required after discharge to continue rapid recovery? J Arthroplasty. 2015;30(4):527-530. 
11. Berkowitz SA, Hulberg AC, Standish S, Reznor G, Atlas SJ. Addressing unmet basic resource needs as part of chronic cardiometabolic disease management. JAMA Intern Med. 2017;177(2):244-252.

12. Blueprint for a Healthier America 2016: Policy Priorities for the Next Administration and Congress. Trust for America's Health. http:// healthyamericans.org/report/129/. Accessed June 30, 2017.

13. Bikdeli B, Wayda B, Bao $H$, et al. Place of residence and outcomes of patients with heart failure: analysis from the telemonitoring to improve heart failure outcomes trial. Circ Cardiovasc Qual Outcomes. 2014;7(5):749-756.

14. Chetty R, Stepner M, Abraham S, et al. The association between income and life expectancy in the United States, 2001-2014. JAMA. 2016;315(16):1750-1766.

15. Health, United States, 2015: with Special Feature on Racial and Ethnic Health Disparities. Hyattsville, MD: National Center for Health Statistics; 2016.

16. Chapman DA, Kelley L, Woolf SH. Life expectancy maps. 20152016. Virginia Commonwealth University Center on Society and Health. http://www.societyhealth.vcu.edu/maps. Updated Apr 14, 2017. Accessed Mar 21, 2017.
17. National Academies of Sciences, Engineering, and Medicine. Communities in Action: Pathways to Health Equity. Washington, DC: The National Academies Press; 2017. doi:https://doi. org/10.17226/24624.

18. U.S. Department of Health and Human Services, Office of the Assistance Secretary for Health. Public health 3.0: A call to action to create a 21st century public health infrastructure. https://www. healthypeople.gov/2020/tools-resources/public-health-3.

19. DeSalvo KB. New Orleans rises anew: Community health after Katrina. Ann Intern Med. 2016;164(1):57-58. 10.7326/M15-2284.

20. Mays CP, Mamaril CB, Timsina LR. Preventable death rates fell where communities expanded population health activities through multi-sector networks. Health Aff. 2016;35(11):205-213.

21. Bradley EH, Elkins BR, Herrin J, Elbel B. Health and social services expenditures: associations with health outcomes. BMJ Qual Saf. 2011;20(10):826-831.

\title{
EDITORIAL
}

\section{Now is the Time to Address Substance Use Disorders in Primary Care}

\author{
Richard Saitz, MD, MPH, FACP, DFASAM ${ }^{1}$ \\ Timothy P. Daaleman, DO, MPH \\ 'Boston University School of Public Health, Boston, Massachusetts \\ ${ }^{2}$ Department of Family Medicine, University of North Carolina at Chapel Hill, Chapel Hill, North Carolina
}

Ann Fam Med 2017;15:306-308. https://doi.org/10.1370/afm.2111.

A lthough over 21 million people in the United States have substance use disorders, most individuals with addiction do not receive treatment. ${ }^{1}$ Of those who are fortunate enough to receive therapy, less than $7 \%$ access it through their doctor. ${ }^{2}$ In addition, fewer than $10 \%$ of people with opioid use disorder in specialty care receive buprenorphine. ${ }^{3}$

Primary care physicians are on the front lines of this epidemic and we see it in the faces and stories of our

Conflicts of interest: See online at bttp://www. annfammed.org/content/15/4/306/ suppl/DC1

\section{CORRESPONDING AUTHOR}

Richard Saitz, MD, MPH, FACP, DFASAM

Boston University School of Public Health

801 Massachusetts Avenue, Ste 433

Boston, MA 02118

rsaitz@bu.edu patients: in the night sweats or gastrointestinal symptoms that are due to alcohol or opioid withdrawal in the anxiety symptoms that are associated with cocaine use $_{i}$ in managing chronic pain that raises concerns about possible addiction. We are good at managing people with many coexisting conditions, and at prioritizing and knowing when we and our patients need specialists. The current opioid epidemic and marginalization of substance use disorders away from primary care has been a disaster, however, and it is a marker for the overextension of primary care. The most complex functions in health care-the much needed integrating, prioritizing, and personalizing care across prevention, acute illness care, mental health care, and management of multiple chronic illnesses_crammed into 10 minutes.

This issue of Annals of Family Medicine contains several studies that address substance use disorders and may point to a way forward for primary care physicians. The study by Anderson and colleagues found that primary 